\title{
Motricidade (pós)humana e a abordagem sobre o corpo na era da simulação
}

\author{
(Post) human motricity and the body approach in the age of simulation
}

La motricidad (post)humana y el enfoque del cuerpo en la era de la simulación

\author{
GiSEle MARIA SCHWARTZ ${ }^{1}$ \\ Universidade Estadual Paulista "Júlio de Mesquita Filho", UNESP, Rio Claro-SP, Brasil
}

\begin{abstract}
RESUMO
O prisma das mudanças impressas pelas eras digital e pós-digital é imenso e infindável, porém, a magnitude de envolvimento com as tecnologias depende do modo como se tem acesso às informações e dos arranjos sociais deflagrados pela necessidade de adaptação aos novos paradigmas. Entretanto, nem sempre, esses avanços foram pautados apenas nas necessidades humanas de resolver algum tipo de problema. Em algum momento e de alguma forma, percebe-se que a fonte de inspiração para a materialização desses recursos extrapola o âmbito da necessidade e se estabelece nas esferas do desejo e do prazer. Pensar como o Profissional da área de Motricidade Humana se insere neste contexto e se apropria dos recursos digitais para atualizar e dinamizar sua prática, representou o desafio deste ensaio, haja vista que esta relação ainda causa estranheza e necessita mais aprofundamento.

Palavras-chave: Motricidade Humana. Ambiente Virtual. Lazer. Educação. Formação Profissional.
\end{abstract}

\begin{abstract}
The prism of the changes printed by digital and post-digital ages is immense and endless, but the magnitude of involvement with technologies depends on the way information is accessed and the social arrangements triggered by the need to adapt to new paradigms. However, not always, these advances were based only on human needs to solve some kind of problem. At some point and in some way, it can be seen that the source of inspiration for the materialization of these resources goes beyond the realm of necessity and is established in the spheres of desire and pleasure. Thinking how Human Motricity Professional fits into this context and appropriates digital resources to update and streamline their practice, represented the challenge of this essay, given that this relationship still causes strangeness and needs further study.

Keywords: Human Motricity. Virtual environment. Recreation. Education. Professional qualification.

\section{RESUMEN}

El prisma de los cambios impresos por la era digital y post-digital es inmenso e interminable, pero la magnitud de la participación con las tecnologías depende de la forma en que se accede a la información y los arreglos sociales provocados por la necesidad de adaptarse a nuevos paradigmas. Sin embargo, no siempre, estos avances se basaron solo en las necesidades humanas para resolver algún tipo de problema. En algún momento y de alguna manera, se puede ver que la fuente de inspiración para la materialización de estos recursos va más allá del ámbito de la necesidad y se establece en las esferas del deseo y el placer. Pensar cómo el Profesional de la Motricidad Humana encaja en este contexto y se apropia de los recursos digitales para actualizar y racionalizar su práctica, representó el desafío de este ensayo, dado que esta relación todavía causa extrañeza y necesita más estudio.
\end{abstract}

Palabras clave: Motricidad humana. Entorno virtual Ocio Educación. Formación profesional.

1 Pesquisadora do LEL-Laboratório de Estudos do Lazer, DEF/IB/UNESP-Rio Claro-SP. E-mail: gisele.schwartz@unesp.br

Motricidades: Rev. SPQMH, v. 3, n. 3, p. 213-221, set.-dez. 2019| ISSN 2594-6463 |

DOI: http://dx.doi.org/10.29181/2594-6463.2019.v3.n3.p213-221 


\section{INTRODUÇÃO}

São completamente irrefutáveis as contribuições atribuídas aos avanços tecnológicos para o desenvolvimento humano. As mudanças historicamente comprovadas podem ser percebidas nos diversos setores da sociedade (HUANG et al., 2019; SAVIN-BADEN; BURDEN, 2019).

No campo do trabalho, desde as primeiras ferramentas forjadas pelo ser humano para aprimoramento da caça, pesca e subsistência, até à qualidade, eficácia, economia (de tempo, espaço e financeira) e dinamismo impressos nas ações, o progresso tecnológico aponta para novos aspectos voltados à otimização de esforços, encurtamento de espaços e tempo e ampliação das relações. Além disto, há outras variáveis também relevantes associadas a esse setor das tecnologias, envolvendo o custo-benefício de produtos, os processos de divulgação, comunicação (de imagens e conteúdos), armazenamento e networking (RAGHURAM et al., 2019), os quais, atualmente, estão baseados no emprego de recursos tecnológicos, sobretudo, aqueles que se relacionam ao ambiente virtual e às redes (não mais feitas apenas de tramas de tecidos, porém, agora, de circuitos de conexões interpessoais!).

$\mathrm{Na}$ esfera das Ciências em geral, envolvendo, sobretudo, o âmbito da Saúde, o progresso tecnológico também se fez presente e representou, marcadamente, uma evolução sem precedentes. O desenvolvimento e o sucesso de pesquisas para ampliar a sobrevida humana estão comprovados e podem ser ratificados pelos principais índices de aumento de anos de vida na maior parte das sociedades do planeta, bem como, pelo impacto da inteligência digital nos arranjos terapêuticos, nos diagnósticos e nos medicamentos utilizados atualmente (VAN GROOTVEN; VAN ACHTERBERG, 2019).

No que concerne ao campo da Educação, os avanços também foram notórios. Podem ser apontadas como exemplo as alterações nos recursos materiais, em que os tradicionais cadernos de anotações são, de certa forma, cada vez mais, substituídos pelos tablets e os volumes impressos de dicionários e enciclopédias, pelos livros e dados expressos de forma online. Até mesmo as ações pedagógicas foram afetadas, com a chegada dos ambientes virtuais de aprendizagem (HUANG et al., 2019) e dos recursos digitais, como no caso do ensino a distância (EAD). Esta modalidade educacional apresenta uma característica peculiar para propiciar a interação docente-discente, sendo mediada pela tecnologia, sem a necessidade de que estes estejam no mesmo ambiente presencial para que o processo ensino-aprendizagem ocorra. Neste formato, o Professor busca elaborar e organizar conteúdos e maneiras diversificadas de passar o conhecimento por meio do ambiente virtual, com base nos recursos tecnológicos disponíveis.

As possibilidades de experiências no contexto do Lazer e do entretenimento, assim como as diferentes formas de expressão na Arte, foram também ampliadas, haja vista as novas interações propostas pela era pós-digital (TAURION, 2017). Já não há necessidade de um pincel (aquele dotado de cerdas) para se executar uma obra de arte, quando se utiliza o ambiente virtual e os recursos de tecnologias digitais, assim como, qualquer pessoa pode se tornar um personagem, como em uma peça de teatro, forjando sua própria identidade online (avatar), do modo como lhe aprouver. As maneiras de se divertir no tempo disponível foram ampliadas, na medida em que o acesso a jogos, por exemplo, pode se dar sem a presença física em determinado local apropriado para uma partida, no caso da prática esportiva, sendo possível jogar (contra a máquina, ou com outras pessoas), ou presenciar uma partida de algum jogo ou esporte como espectador, utilizando os recursos da virtualidade. 
O prisma das mudanças impressas pelas eras digital e pós-digital é imenso e infindável, podendo ser ainda maior, dependendo do modo como se tem acesso às informações e dos arranjos sociais deflagrados pela necessidade de adaptação aos novos paradigmas. Entretanto, nem sempre, esses avanços foram pautados apenas nas necessidades humanas de resolver algum tipo de problema. Em algum momento e de alguma forma, percebe-se que a fonte de inspiração para a materialização desses recursos extrapola o âmbito da necessidade e se estabelece nas esferas do desejo e do prazer.

Ao se pensar desta forma, ressalta, entre várias, uma curiosidade, por saber se aquela famosa pirâmide referente às hierarquias das necessidades humanas desenvolvida por Maslow (1970) ainda seria adequada, na atualidade, para se compreender sobre as necessidades, os processos de motivação e as personalidades que se apresentam na atualidade. Em seu estudo, Maslow (1970) evidenciou que as necessidades básicas de subsistência (fisiológicas) eram as que o ser humano procurava suprir em primeiro plano, para se sentir bem, sendo seguidas pelas necessidades de segurança, relacionamentos, autoestima e autorrealização.

$\mathrm{Na}$ era da simulação, onde a virtualidade impera e a presença in loco (física, no local) já pode ser relativizada (para não dizer substituída) pela presença virtual (online, não-presença presente), as necessidades humanas parecem ter sido alteradas, o que mereceria revisitar as bases da teoria anteriormente proposta por Maslow. Atualmente, o desejo de subsistência parece envolver, agora, outras variáveis, não apenas as fisiológicas. Parecem merecer muita consideração e ter direta relação com a fisiologia (sobretudo das emoções) a necessidade de se ter baterias para celulares ou tablets carregadas, ou de se possuir acesso irrestrito à internet. Portanto, inúmeras alterações no modus vivendi foram sendo estabelecidas, para contemplar essas novas necessidades humanas dentro do progresso existencial, as quais merecem atenção e atualização constantes.

Com tudo isto acontecendo, a humanidade tem passado por exigentes transformações em seus valores éticos e morais, haja vista que nem tudo são flores, quando se fala em evolução tecnológica. Paradoxalmente, a sociedade almeja o progresso tecnológico, com o intuito de promover o bem-estar, porém, com esse avanço, ela também se vê envolta na trama de que a perspectiva desse mesmo progresso pode acelerar seu próprio fim, dependendo do desejo de alguém que queira, simplesmente, apertar um botão capaz de destruir parte da humanidade que não comungue com sua ideologia. Este progresso, por conseguinte, envolve efetivamente um paradoxo entre necessidades e desejos (alguns tipos ainda contidos, por sorte!).

Enquanto isto não acontece, há vida e há que se promoverem inúmeras adaptações nas esferas sociais humanas, atendendo, tanto às necessidades, quanto aos desejos, os quais influenciam as escolhas humanas e delineiam estilos do viver. Hoje em dia, há uma forma de viver bastante própria, que se estabelece no contexto virtual. Baseado nesse prisma que se apresenta fortemente, seria adequado dizer que se vive no paradigma da pós-humanidade, conforme ressaltaram Santaella (2007, 2016), Tavares (2006) e Araújo (2017)?

Atentos para essas mudanças claramente estabelecidas, Santaella (2007, 2016), Tavares (2006) e Araújo (2017) reiteram uma reflexão interessante, a respeito de uma nova forma conceptual para esse paradigma atual - a pós-humanidade. Segundo esses estudiosos, esse termo não se restringe a ultrapassar o humano, como se este já não fizesse parte da tessitura social, mas sim, diz respeito à perspectiva de o ser humano constituir suas habilidades, competências e valores, agora, na estreita relação com o não-humano, no caso, as máquinas e os equipamentos tecnológicos (ARAÚJO, 2017). 
A ampliação dos limites de compreensão sobre o corpo, agora podendo estar também presente virtualmente, é notória, exigindo, inclusive, novas concepções para tempo, espaço e construção simbólica da corporeidade, temáticas importantes, as quais representam um grande desafio para serem discutidas no contexto da Motricidade Humana, compreendida por Gonçalves Júnior (2009, p. 701) como "[...] movimento intencional de transcendência, portanto, do ser no contexto do mundo." Sérgio e Lemos (2019) ratificam esta mesma perspectiva, enfatizando a intersubjetividade envolvida nas experiências humanas.

Ainda acerca do conceito de pós-humanidade Santaella (2007; 2016), Tavares (2006) e Araújo (2017) destacam que a pós-modernidade reafirmou a modernidade, sendo assim, a pós-humanidade estaria ratificando exatamente a humanidade. Entretanto, a alteração está justamente nas relações do corpo com as tecnologias e, sobretudo, com a virtualidade, exigindo o que Araújo (2017) propôs como uma ressignificação da concepção atual de corpo, levando em conta a necessidade de redimensionar sua percepção, o delineamento de valores, seu modo de ser-no-mundo, com base na proclamada cibercultura (ARAÚJO, 2010). Esse termo evoca a estreita relação humana com as tecnologias, advinda de uma grande evolução nesse setor (LEMOS, 2003; LEMOS, 2008).

Este novo modo de pensar a corporeidade aliada à virtualidade, alarga a percepção de corpo para além da presença física tangível (in loco), o que deflagra inúmeras alterações na sociedade. Ao se focalizar o ambiente virtual, evidenciam-se algumas características peculiares, em que se percebe que as experiências ocorrem de forma diferente do que normalmente sucedem no ambiente fora do virtual, uma vez que estas não são meramente uma cópia, pois podem ser exacerbadas, ou também, ofuscadas, quando há alteração nessa ambiência. Outra característica é que os que participam dessas vivências no virtual deixam de representar apenas consumidores de determinada experiência, mas, têm a capacidade de se tornar coadjuvantes, ou mesmo, protagonistas e cocriadores dessa experiência, a qual pode ser vivenciada simultaneamente por diversos atores sociais, de forma concomitante.

A diversidade de ofertas é bastante ampliada pela flexibilidade e mobilidade das formas de ação, diferente de outras práticas que possuem limites de tempo e espaço definidos e padronizados. Os diversos conjuntos de desafios e tarefas a serem executados estão atrelados e atendem a motivos diversos de engajamento, buscando a construção de realidades variadas. Ainda, o ambiente virtual promove mais liberdade de expressão, mais facilidade de se viver a sensação de empoderamento e de criação.

De modo geral, os estudos sobre essa temática já evidenciam que as experiências provenientes do ambiente virtual auxiliam na redução da sensação de medo do engajamento nas atividades. Isto é capaz de ampliar a autoconfiança e induzir à busca pela aventura no âmbito virtual, pela vivência do lúdico e pela possibilidade de se experimentar maior cooperação e compartilhamento (ZICHERMANN, 2011). O mundo digital, segundo ressalta Santaella (2016), requer que as pessoas efetivamente mergulhem nas ações práticas que este novo olhar pressupõe, tornando-se um habitante protagonista de seu próprio mundo.

Surgem, assim, outras inquietações para adensar as reflexões: será que os pressupostos das vivências no ambiente virtual são exatamente opostos aos da Motricidade Humana? Como o Profissional da área de Motricidade Humana pode se apropriar dos recursos da internet e do ambiente virtual para atualizar e dinamizar suas ações?

Ao se refletir sobre tudo isto no âmbito da Motricidade Humana, percebe-se que esta relação ainda causa estranheza e necessita mais aprofundamento. Entender que o 
movimento humano também é possível no ou pelo espaço virtual traz muitos desafios para a área, haja vista que as formas de se lidar com novos modos de ensinar e aprender, com a ampliação e diversificação de tipos de práticas e com a adequação a outros princípios pedagógicos, necessitam atualização constante, a fim de atender às demandas da atualidade.

Ao longo da formação do Profissional atuante na área da Motricidade Humana, raramente ele recebe alguma informação específica, ou é colocado em uma situação reflexiva acerca das novas formas de se movimentar, para introduzir as especificidades exigidas na atualidade. Em inúmeras Universidades ou em cursos de formação, ainda não são oferecidas disciplinas, nem mesmo conteúdos específicos para discussão sobre esses assuntos, levando em consideração essas relações do corpo com o ambiente virtual.

Com o advento da internet, o ambiente virtual passou a fazer parte das tendências sociais e do estilo de vida de quase todas as culturas. Ao se tomar como foco os interesses atuais de crianças, jovens, adultos e idosos sobre atividades do ambiente virtual, percebe-se, ainda, muita incongruência, já que os recursos, os conteúdos das práticas e os modos de ensino convencionalmente disponibilizados na área deixam de atender a essas expectativas, parecendo não acompanhá-las adequadamente.

Entretanto, algumas ações isoladas de docentes preocupados em atender a essas novas demandas começam a ser notadas, com alguns exemplos que podem auxiliar na alteração desses processos e na abordagem da relação corporal com o ambiente virtual e facilitar a inserção nesse universo de possibilidades. Isto posto, são apresentadas a seguir alguns elementos, almejando subsidiar as reflexões no contexto da Motricidade Humana.

Entre as opções atuais que se fazem presentes mais prontamente, pode ser citada como exemplo a utilização de filmes, vídeos, recursos de aplicativos, sites para buscas de informações e o sistema de Educação à Distância. Esses recursos promovem inúmeras aplicações, sendo úteis para estudar certas modalidades esportivas, conhecer atividades que não são viáveis de serem executadas na prática (a exemplo do kitesurf), acompanhar informações e transmissões das mídias (grandes eventos) e ampliar os conhecimentos sobre determinado tema (histórias e personagens de determinada modalidade esportiva).

Pautados na impossibilidade de desfazer a relação amalgamada entre os recursos virtuais e a vida cotidiana atual, os Profissionais do campo da Motricidade Humana necessitam atualização constante, para trazerem novas vivências para os ambientes escolares e não-escolares em que atuam. Assim, outra forma bastante apropriada é levar em conta os pressupostos da gameficação, cujo conceito prevê a utilização das formas mecânicas de recursos técnicos e das dinâmicas associadas aos jogos, em outras realidades distantes daquela propriamente vivenciada para diversão e entretenimento.

As características desse recurso promovem maior dinamismo nas situações, motivando o envolvimento, a curiosidade e novas maneiras de solucionar os desafios e problemas apresentados, por meio de metas claramente definidas. Estas características associadas à utilização de recursos tecnológicos dos dispositivos eletrônicos móveis são capazes, inclusive, de afetar o aprendizado e potencializar a promoção e o desenvolvimento de novas atitudes e condutas (ARAÚJO; FREITAS, 2018; CAMUCI; MATTHIESEN, 2017; ARAÚJO; SOUZA; MOURA, 2017).

São exemplos de atividades de gameficação, os jogos eletrônicos, os exergames, os fisiogames e os e-Sports. O envolvimento de tecnologias de realidade virtual nas práticas corporais pode ter como intuito o oferecimento de processos terapêticos 
inovadores, de motivação para treinamento de habilidades esportivas específicas, de aprendizado de novas práticas e, inclusive, formas de entretenimento e recreação.

Outro modo de apropriação desses elementos tem sido demonstrado com uma iniciativa bastante exitosa denominada webgames com o corpo (SCHWARTZ et al., 2013; SCHWARTZ; TAVARES, 2015), voltada à simulação de atividades. Esta proposta vivifica uma adaptação de estímulos que são advindos das atividades de jogos do ambiente virtual, corporificando a experiência, com base na simulação desses estímulos. Conforme esses autores, estas vivências apresentam vantagens para o desenvolvimento da imaginação e criatividade, promovendo a superação de limites pessoais, o enriquecimento do repertório motor, representando uma estratégia importante, inclusive, para estímulo à prática regular de exercícios físicos.

No campo de ação da Motricidade Humana, diversos jogos virtuais possuem potencial para que sejam simulados com o corpo, dependendo da habilidade do próprio Profissional para que isto ocorra de modo adequado às necessidades. Estes recursos podem ser também utilizados como modelos para a criação de novos jogos ou de releitura de outros jogos e atividades lúdicas mais tradicionais, como os jogos de tabuleiro com o corpo, sobretudo, para amplificar a educação para o lazer (SCHWARTZ et al., 2016). Como exemplo, pode ser citada a utilização do Instagram $($ ) ou do WhatsApp $@$, para divulgação de tarefas a serem cumpridas, ou no contexto de um caça-ao-tesouro. Estes tipos de jogos de simulação podem ser inseridos no âmbito educacional, na recreação e na esfera do trabalho, já que suas dinâmicas favorecem diversas habilidades.

Ainda não se discute adequadamente, também, os $e$-Sports. Essas atividades vêm recebendo atenção, na atualidade, sendo consideradas como modalidades esportivas e difundidas como novos esportes, com ligas, torcidas, treinamentos específicos e Confederações nacionais e internacionais, as quais gerenciam atletas e eventos (SILVA et al., 2018). Porém, este assunto ainda não se faz efetivamente presente nas discussões sobre os esportes na área de Motricidade Humana. Portanto, não se têm as devidas reflexões e esclarecimentos se este tipo de atividade pode ser considerada esporte e fazer parte da área. Ao considerá-los esporte, ainda não se conhecem suas potencialidades educacionais, os treinamentos mais adequados para estas modalidades, as formas de acompanhamento psicológicos das equipes e o modo mais eficaz de se introduzir essa temática nesse campo de ação. Falta, portanto, mais riqueza nas reflexões da área, sobretudo no que concerne à formação e ao campo de atuação desse Profissional.

A gameficação e a simulação de jogos representam agentes transformadores da cultura, haja vista que podem ser utilizados por Profissionais das mais diversas áreas, para melhoria de estratégias de enriquecimento (e atualização) de suas ações. Porém, para que isto se estabeleça, é necessário que esse Profissional possa conhecer essas possibilidades e adaptar-se a essas realidades em constante transformação, compreendendo que novos paradigmas para o movimento humano emergem da virtualização do corpo.

À guisa de conclusão deste ensaio, o Profissional do campo da Motricidade Humana necessita compreender o corpo como multifacetado, tendo suas fronteiras de concepção alargadas e permeadas pelas transformações culturais (agora envolvendo também a cibercultura!). Com isto, poderá ampliar a percepção dos novos significados evocados pelos sujeitos, ao longo dessa aventura inédita de cocriação.

A formação na área de Motricidade Humana precisa acompanhar as tendências atuais e, para tanto, há que alargar as possibilidades de atualização urgente de seus conteúdos. Os elementos que envolvem as bases da inteligência artificial e seus 
impactos exponenciais na cultura ainda serão responsáveis por provocar diversas novas alterações sociais sem precedentes e sem possibilidade de serem refreadas.

No mundo, diversos países estão readequando o desenho de estratégias de estado, buscando se pautar na inteligência artificial para aprimorar a Educação e a Política, conforme salienta Taurion (2017). Para tanto, os dirigentes levam em consideração que, ainda que a máquina ou qualquer equipamento tecnológico seja capaz de fazer cálculos de modo mais eficiente, rápido e preciso, torna-se fundamental enfatizar modelos de formação que priorizem o desenvolvimento de empatia, criatividade, senso crítico e de inovação, competências próprias do ser humano e que serão vitais de serem enfatizadas para as futuras profissões.

Novas noções sobre compartilhamento devem ser refletidas, uma vez que este termo, não mais diz respeito apenas a ter que possuir determinado objeto que pode ser emprestado para outras pessoas, mas, agora, também assume a perspectiva de divisão de utilização de um objeto por muitos usuários, sem ter a posse efetiva do mesmo. Esta é uma forma inovada e criativa de pensar o consumo, a educação e os valores. Porém, segundo Taurion (2017), o Brasil, também em seu sistema educacional, ainda é inóspito para tudo o que diz respeito à inovação e à criatividade, haja vista a burocracia que ainda emperra a máquina pública.

Torna-se, portanto, crucial que haja uma transformação do modelo educacional, buscando incentivar a formação de profissionais em geral, e da Motricidade Humana em particular, capacitados para assumir as contingências da atualidade. Esta transformação deve incidir, inclusive, sobre a necessidade de formações crítica e criativa consistentes, capazes de respaldar a autotransformação e a consolidação de atitudes equilibradas acerca da aplicação adequada e dos papéis (positivo e negativo) dos recursos tecnológicos na área da Motricidade.

Algumas áreas de formação podem até desaparecer, assim como outras poderão ser criadas, dependendo da demanda. Sendo assim, o campo da Motricidade Humana deverá antever o futuro e preparar o profissional com competências e habilidades que ainda deverão ser devidamente desenvolvidas. As tecnologias cognitivas (envolvendo a inteligência artificial) ajudam a desenvolver a velocidade e a amplitude das ações, mas, mais do que isto, são capazes de potencializar a capacidade cognitiva (TAURION, 2017). Esta geração atual é a primeira que irá enfrentar a necessidade urgente da mudança, já que o que está posto hoje pode não ser parte do futuro (próximo).

Para que isto possa representar uma realidade, é fundamental que as Políticas Públicas voltadas ao desenvolvimento do sistema educacional superem o modelo atual (na maioria das vezes, engessado e burocratizado!) e consiga efetivamente formar um quadro de atuantes com visão no futuro e nas funções que serão exigidas. Da mesma forma, é imprescindível que o próprio Profissional seja burilado no sentido de desenvolver o autoaprendizado, com atitudes e condutas proativas, buscando conhecimento, pesquisando formas de inovação e estratégias para assimilar as mudanças que afloram vivamente como necessárias a uma boa atuação nesta nova era.

Esta era pós-digital deixa muito tênue a fronteira e interface entre as esferas biológica, física e digital. O delineamento de novos processos advindos da inclusão de inteligências e modelos diferenciados e diversificados de pensar introduzem novos benefícios, propiciando mais simplicidade (mesmo sob a complexidade de uma máquina), conveniência, preço e efetividade das ações. Porém, a percepção sobre bemestar, felicidade, prazer e beleza está no olhar (e na sensibilidade) do humano.

Por fim, para que a relação do Profissional da Motricidade Humana com esses estímulos provenientes da virtualidade e da era pós-digital seja exitosa, é necessário que ele supere os preconceitos ainda arraigados, acerca da utilização desses recursos 
tecnológicos nesse âmbito. Isto só será possível, se o Profissional demonstrar abertura para mudanças, sendo protagonista de seu espaço social.

Em síntese, a valorização de novas exigências no mundo da Motricidade Humana deve ser catalisadora de alterações no ambiente pedagógico, em que se considere a ampliação do repertório das práticas corporais condizentes com os interesses da atualidade. É vital, também, que os cursos de formação na área estejam atentos a essas novas demandas, procurando atualizar sua concepção, ampliando as reflexões no bojo curricular e as perspectivas de mudanças de valores, pautando-se no conhecimento e no comprometimento social.

Pensar, na atualidade, o corpo sensível em movimento, em sincronia com a (ciber)cultura, se torna o grande desafio para a Motricidade Humana. Tudo o que é novo induz ao risco, mas também, apresenta novas possibilidades de criar. Seria possível tentar?

\section{REFERÊNCIAS}

ARAÚJO, B. M. R.; FREITAS, C. M. S. M. Dos jogos tradicionais aos virtuais: os jogos eletrônicos e o processo de virtualização esportiva e corporal. In: CAMINHA, I. O.; SOUTO, G.M.S. (Orgs.). Educação física e as reviravoltas do corpo. Curitiba: Appris, 2018, v. 1, p. 77-90.

ARAÚJO, B. M. R. A virtualização esportiva nos jogos eletrônicos e os novos paradigmas para o movimento humano. 2010. 126 p. Dissertação (Mestrado em Educação Física - Cultura, Educação e Movimento Humano) - Programa Associado de Pós-graduação em Educação Física, Universidade de Pernambuco, Universidade Federal da Paraíba, Recife, 2010. Disponível em: < http://w2.files.scire.net.br/atrio/upe-papgef_upl//THESIS/60/bruno_medeiros_roldo_de_arajo.pdf> Acesso em: 07 nov. 2018.

ARAÚJO, B. M. R.; FREITAS, C. M. S. M.; CAMINHA, I. O.; SILVA, P. P. C. Virtualização esportiva e os novos paradigmas para o movimento humano. Motriz, Rio Claro, v. 17, n. 4, p. 600-609, 2011.

ARAÚJO, B. M. R.; FREITAS, C. M. S. M. O corpo virtualizado do ciberjogador. In: CATTUZZO, M. T.; CAMINHA, I. O. (Orgs.). Fazer e pensar ciência em educação física - Livro I. João Pessoa: Editora Universitária da UFPB, 2012. p. 267-287.

CAMUCI, G. C.; MATTHIESEN, S. Q.; GINCIENE, G. O jogo de videogame relacionado ao atletismo e suas possibilidades pedagógicas. Motrivivência, Florianópolis, v. 29, n. 50, p. 62-76, 2017.

GONÇALVES JUNIOR, L. Dialogando sobre a capoeira: possibilidades de intervenção a partir da motricidade humana. Motriz, Rio Claro, v. 15, n. 3, p. 700-707, 2009.

HUANG, Yu-C.; BACKMAN, S. J.; BACKMAN, K. F.; MCGUIRE, F. A.; MOORE, D. An investigation of motivation and experience in virtual learning environments: a self-determination theory. Education and Information Technologies, Cham, v. 24, n. 1, p. 591-611, 2019.

LEMOS, A. Cibercultura: tecnologia e vida social na cultura contemporânea. 4. ed. Porto Alegre: Sulina, 2008.

LEMOS, A. Cibercultura: alguns pontos para compreender a nossa época. In: LEMOS, A.; CUNHA, P. (Orgs.). Olhares sobre a cibercultura. Porto Alegre: Sulina, 2003. p. 11-23.

MASLOW, A. H. Motivation and personality. 2. ed. New York: Harper and Row, 1970.

RAGHURAM, S.; HILL, N. S.; GIBBS, J. L.; MARUPING, L. M. Virtual work: bridging research clusters. Academy of Management Annals, Briarcliff Manor, v. 13, n. 1, p. 308-341, 2019.

SANTAELlA, L. Temas e dilemas do pós-digital: a voz da política. 1. ed. São Paulo: Paulus, 2016. 
SANTAELLA, L. Pós-humano: por quê? Revista USP, São Paulo, v. 1, n. 74, p. 126-137, 2007.

SAVIN-BADEN, M.; BURDEN, D. Digital immortality and virtual humans. Postdigital Science and Education, New York, v. 1, n. 1, p. 87-103, 2019.

SCHWARTZ, G. M.; TAVARES, G. H. (Orgs.). Webgames com o corpo: vivenciando jogos virtuais no mundo real. 1. ed. São Paulo: Phorte, 2015.

SCHWARTZ, G. M.; SANTIAGO, D. R. P.; KAWAGUTI, C. N.; TAVARES, G. H.; FIGUEIREDO, J. P.; PALHARES, M. F. S.; NASCIMENTO, A. M. Apropriação das tecnologias virtuais como estratégias de intervenção no campo do lazer: os Webgames adaptados. Revista Licere, Belo Horizonte, v. 16, n. 3, 2013.

SCHWARTZ, G. M.; TEODORO, A. P. E. G.; RODRIGUES, N. H.; DIAS, V. K. Educando para o lazer. 1. ed. Curitiba: CRV, 2016.

SÉRGIO, M.; LEMOS, F. R. M. Futebol: necessárias rupturas. Motricidades: Rev. SPQMH, v. 3, n. 1, p. 69-76, 2019.

SILVA, R. L.; TAVARES, G. H.; PACHECO, J. P. S.; FUKUSHIMA, R. L. M.; SCHWARTZ, G. M. Violência de gênero no âmbito dos e-sports: uma revisão sistemática. In: CONGRESSO INTERNACIONAL DE PSICOLOGIA DO ESPORTE, DESENVOLVIMENTO HUMANO E TECNOLOGIAS, 4., CONGRESSO NACIONAL, 7., e SEMINÁRIO DE PSICOLOGIA DA MOTRICIDADE HUMANA, ESPORTE, RECREAÇÃO E DANÇA, 10., 2018, Rio Claro. Anais... Rio Claro, 2018. p. 112. Disponível em:< https://32cc02a7-f136-43f8-ae8e936d68461e08.filesusr.com/ugd/a2928f_3a5405b1223040c7a362dc0bc39e8c3d.pdf> Acesso em: 07 nov. 2018.

TAURION, C. Tecnologias emergentes: Mudança de atitude e diferenciais competitivos nas empresas. 2. ed. São Paulo: Évora, 2017.

VAN GROOTVEN, B.; VAN ACHTERBERG, T. The European Union's ambient and assisted living joint programme: an evaluation of its impact on population health and well-being. Health Informatics Journal, Thousand Oaks, v. 25, n. 1, p. 27-40, 2019.

Recebido em: 07 nov. 2019.

Aprovado em: 04 dez. 2019. 